\title{
The Puborectal Muscle and External Anal Sphincter Can Act Independently of each other in Functional Defecation Disorders
}

\author{
Hielke KH de Boer ${ }^{1}$, Monika Trzpis ${ }^{1}$ and Paul MA Broens ${ }^{1,2 *}$ \\ ${ }^{1}$ Department of Surgery, Anorectal Physiology Laboratory, University of Groningen, University Medical Center Groningen, Groningen, the Netherland \\ ${ }^{2}$ Department of Surgery, Division of Pediatric Surgery, University of Groningen, University Medical Center Groningen, Groningen, the Netherlands
} Submission: March 23, 2021; Published: April 09, 2021

*Corresponding author: Paul MA Broens, Department of Surgery, Division of Pediatric Surgery, University Medical Center Groningen, P.O. Box 30.001, 9700 RB Groningen, Netherlands

Abstract

Background: Classification currently used for functional defecation disorders (FDDs) assumes that the puborectal muscle and external anal sphincter act as a single functional unit. We hypothesize that the puborectal muscle and external anal sphincter do not act as a single functional unit.

Methods: We performed anorectal manometry and defecometry tests in 124 adult patients suffering from functional defecation disorder. Anorectal manometry provides information about the pressure profile of the anal canal and the distal part of the rectum. The defecometry test provides information about rectoanal coordination during defecation.

Results: We observed that the puborectal muscle and external anal sphincter did not always contribute equally to an FDD. We distinguished three main groups of FDDs: congruent $(n=105)$, anal sphincter-dominated $(n=10)$, and puborectal muscle-dominated $(n=9)$. The propulsive force required to defecate (rectal pressure increase) correlated more strongly with pressure increase at the level of the puborectal muscle ( $\rho=0.794)$ than at the level of the external anal sphincter $(\rho=0.488)$.

Conclusion: We conclude therefore that the puborectal muscle and external anal sphincter do not, by definition, act as a single functional unit in patients suffering from FDDs and may differ in the degree of dyssynergia. Our modified classification of FDDs can significantly improve the proper diagnosis and, therefore, treatment of FDDs. Furthermore, we conclude that isolated high puborectal pressure impedes defecation more than isolated anal sphincter contraction.

Keywords: Chronic constipation; Functional defecation disorder; Dyssynergic defecation; Anorectal function test; Puborectal muscle

\section{Introduction}

Functional defecation disorder (FDD) is a common disorder underlying between 25 to $75 \%$ of cases of functional obstipation [1-4]. Failing rectoanal coordination manifests itself clinically in diminished stool frequency, excessive straining, a feeling of incomplete evacuation, and/or the need to use digital maneuvers to promote defecation $[3,5,6]$. If left untreated a FDD can give rise to serious complications such as fecal impaction and fecal incontinence $[7,8]$.

FDDs can be diagnosed with anorectal manometry and/or the balloon expulsion test [9]. Subsequently, based on the manometric abnormalities, the FDDs can be subdivided into one of several groups or types. The Rome IV classification distinguishes two groups, namely, dyssynergic defecation and inadequate defecatory propulsion. Rao's classification further subdivides these two groups into four types of FDDs (Types I-IV) [10,11]. Both classifications are based solely on abnormal pressure changes in the rectum and at the level of the external anal sphincter, thereby ignoring pressure changes at the level of the puborectal muscle.

Currently, it is assumed that the puborectal muscle and external anal sphincter act as a single functional unit and both simultaneously muscles contract or relax. Based on our clinical observations and measurements obtained in our Anorectal Physiology Laboratory, however, we think that this assumption might mean a major limitation to both the above-mentioned classifications. Since the treatment of patients suffering from FDD is also based on the aforementioned assumption, the efficiency 
of current treatment is questionable. We hypothesize that the puborectal muscle and external anal sphincter do not act as a single functional unit. Therefore, by definition, they are not always equally affected in patients suffering from FDDs.

\section{Materials and Methods}

\section{Participants}

For this study, we retrospectively assessed the results of anorectal function tests conducted in adult patients suffering from monometrically confirmed FDDs. All the 135 patients studied, were referred to our tertiary care center with refractory symptoms of difficult defecation. Eleven patients were excluded for various reasons: faulty measurements $(n=4)$, a history of ileal pouch-anal anastomosis $(n=3)$, anal carcinoma $(n=1)$, diabetic neuropathy $(\mathrm{n}=2)$, or spina bifida $(\mathrm{n}=1)$. Of the remaining 124 patients, 97 were females (the male to female ratio was 1:3.6). The median age of the study population was 57 years (age range: 18 to 81).

\section{Measuring equipment}

We collected and analyzed the data with solar high-resolution gastrointestinal manometry equipment, version 8.23 (Medical Measurement Systems BV, Enschede, the Netherlands). We used two different catheters: a Unisensor K12981 solid state (Boston type) catheter, hereinafter referred to as Catheter 1 , to measure circumferential pressure every $8 \mathrm{~mm}$ over a total length of 6.8 $\mathrm{cm}$ into the rectum and a Unisensor K14204 catheter, hereinafter referred to as Catheter 2, to connect the rectal balloon, to inflate it, and to register the pressure inside the balloon. This pressure was corrected for the resistance of the balloon itself, thus ensuring that we reported only true rectal pressure.

No endoscopic ultrasound and MRI measurements were included in this study since our aim was to investigate the dynamic physiology of the pelvic floor during the defecation process. This can only be illustrated by a combination of various anorectal function tests such as anorectal pressure test and defecometry test.

\section{Anorectal function tests}

Three different anorectal function tests were performed: the anorectal pressure test, the balloon retention test, and the defecometry test.

a) Anorectal pressure test provides information about the pressure profile of the anal canal and the distal part of the rectum. The test was performed with the patient in the left lateral recumbent position, using Catheter 1 . We recorded maximum basal pressure, maximum squeeze pressure, and the length of the anal high-pressure zone.

b) The balloon retention test was used to determine the urge sensation volume. It was performed as described previously [11-13]. While the patient was trying to evacuate the balloon, we recorded the expulsion time (i.e., the duration of the attempt) as well as the pressure profiles at the level of the rectum, puborectal muscle, and external anal sphincter.

c) The defecometry test provides information about patient's rectoanal coordination during defecation and is a combination of the classical anorectal manometry and the balloon expulsion test. We carefully attached Catheter 1 to the patient's buttocks near the anal canal. Next to Catheter 1 we connected a deflated, non-latex balloon to Catheter 2, and placed it in the patient's rectum. During placing the catheters, the patient was in the left lateral recumbent position. We used adhesive tape to prevent Catheter 1 from slipping. After having placed the catheters, we performed the test with the patient sitting upright on a commode. As soon as the patient was completely at ease, we filled the balloon with $50 \mathrm{~mL}$ of water at body temperature. After that, the investigating nurse left the room while the patient had been asked to evacuate the balloon. If the patient was unable to expel it, we increased the volume of water in the balloon with a further $50 \mathrm{ml}$ until reaching urge sensation volume.

During both the balloon retention test and the defecometry test the water was inflated into the balloon with Catheter 2 and the pressure was measured with Catheter 2 unfixed and catheter 1 , which was fixed to the buttocks to prevent its dislocation.

Rectoanal coordination is impaired in patients suffering from FDDs and can be clearly demonstrated by the defecometry test. Not only is it possible to assess the adequacy of the defecatory propulsive force (an intrarectral pressure increase of $\geq 40 \mathrm{~mm} \mathrm{Hg}$ is considered adequate), but one can also demonstrate inadequate relaxation ( $<20 \%$ decrease in pressure) or paradoxical contraction of the puborectal muscle and/or external anal sphincter $[9,10]$. Although failure to expel the balloon is indicative, many patients suffering from FDDs can expel the balloon. In other words, evacuation of the balloon during the defecometry test does not exclude FDD $[14,15]$.

\section{Statistical analysis}

We analyzed the data using SPSS for Windows, version 20.0 (IBM SPSS Statistics, IBM Corporation, Armonk, NY). We used the chi-squared and Fisher's exact tests to compare proportions. We tested all continuous variables for normal distribution using the Shapiro-Wilk test. None of the variables had a normal distribution. Thus, we reported median, minimum, and maximum values. We used the Mann-Whitney and Kruskal Wallis tests for comparison, in which a $p$ value of $\leq 0.05$ was considered significant. To calculate correlations, we used Spearman's rank correlation statistics.

Results

The puborectal muscle and external anal sphincter did not always contribute equally to FDDs. The defecometry test showed that the puborectal muscle and the external anal sphincter did not contribute equally to FDDs in all patients. In most patients 
$(n=105)$ both muscles were affected equally by FDDs (i.e., there was inadequate relaxation or paradoxical contraction in the puborectal muscle and external anal sphincter) (Figure 1A). Nevertheless, in a small number of patients $(n=19)$ we found that either the puborectal muscle or external anal sphincter was affected significantly more than the other. Nine patients had paradoxical contraction of the puborectal muscle, but only inadequate relaxation of the external anal sphincter (Figure 1B). Ten patients had inadequate relaxation of the puborectal muscle, but paradoxical contraction of the external anal sphincter (Figure 1C).

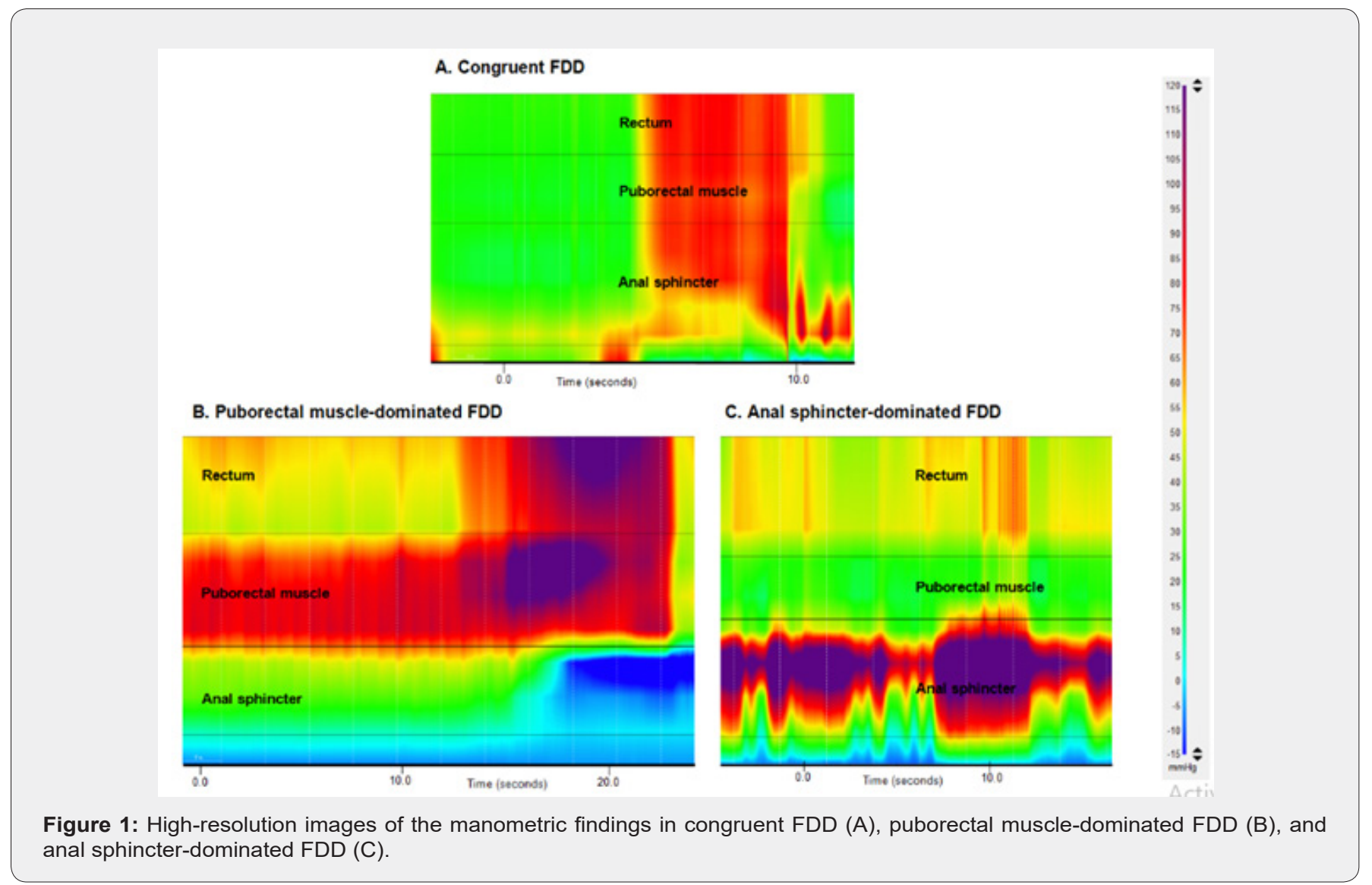

\section{Towards a new classification for FDDs}

The above-mentioned finding prompted us to rethink the current classification systems for FDDs. Instead of a classification that is based on pressure changes in the rectum and at the level of the external anal sphincter alone, we sought a classification that would also consider pressure changes at the level of the puborectal muscle. To this end we modified Rao's classification. It resulted in a classification distinguishing seventeen types of FDDs. Because we did not find patients showing adequate relaxation of the puborectal muscle or the external anal sphincter, we reduced the number of different types of FDD to eight (Figure 2). We described each of these types by a combination of two Roman numerals. The first Roman numeral corresponded to the action of the puborectal muscle in relation to the defecatory propulsive force, while the second Roman numeral corresponded to the action of the external anal sphincter in relation to the defecatory propulsive force (as in Rao's classification).
We illustrate our new classification by presenting two groups of patients classified accordingly:

a) patients who had adequate defecatory propulsive force, paradoxical contraction of the puborectal muscle, and paradoxical contraction of the external anal sphincter we assigned to FDD Type I-I;

b) patients who had inadequate defecatory propulsive force, inadequate relaxation of the puborectal muscle, and paradoxical contraction of the external anal sphincter we assigned to FDD Types IV-II.

For the sake of convenience, we grouped the eight types together to form three main groups of FDDs (Figure 2). First, Types I-I, II-II, III-III and IV-IV we grouped under the heading congruent FDD. In this group of FDDs the puborectal muscle and external anal sphincter were affected approximately equally, i.e., both inadequate relaxation and both paradoxical contractions. Second, Types I-III 
and II-IV formed the group of puborectal muscle-dominated FDD in which the puborectal muscle was affected significantly more than the external anal sphincter, i.e., paradoxical contraction of the puborectal muscle versus inadequate relaxation of the external anal sphincter. Third, Types III-I and IV-II constituted the anal sphincter-dominated group of FDDs in which the external anal sphincter was affected significantly more than the puborectal muscle, i.e., paradoxical contraction of the external anal sphincter versus inadequate relaxation of the puborectal muscle.

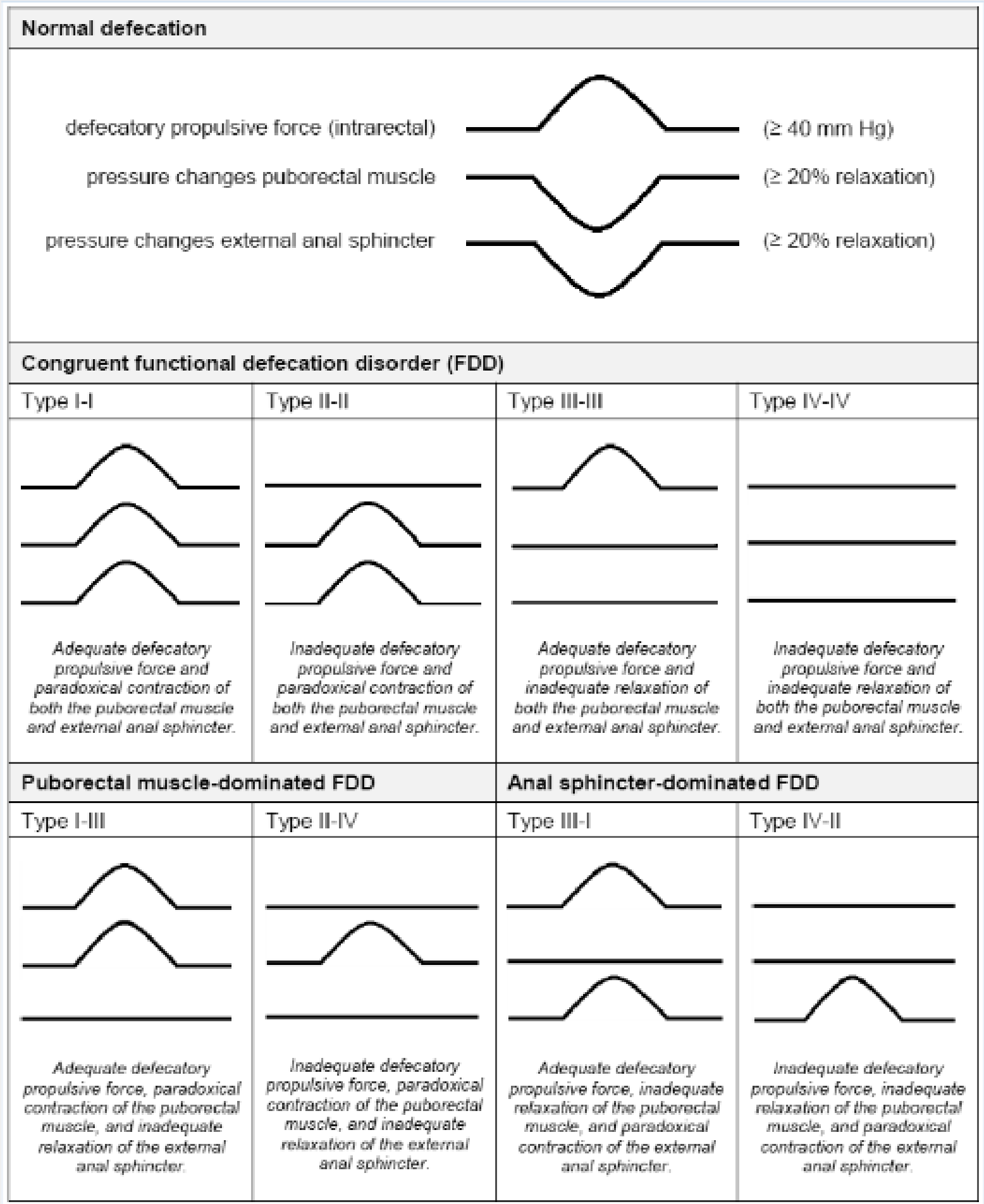

Figure 2: Newly proposed classification system for functional defecation disorders (FDDs). 
The majority of patients suffered from congruent FDD

Grouping the patients according to our new classification showed that $84.7 \%$ of patients $(n=105)$ suffered from congruent
FDD, $7.3 \%$ of patients $(\mathrm{n}=9)$ from puborectal muscle-dominated FDD, and $8.1 \%$ of patients $(n=10)$ from anal sphincter-dominated FDD (Table 1).

Table 1: Frequencies of various subtypes of functional defecation disorders (FDDs).

\begin{tabular}{|c|c|c|}
\hline & Frequency (n) & Percentage of Total \\
\hline Total & 124 & $84.70 \%$ \\
\hline Congruent FDD & 105 & $71.00 \%$ \\
\hline Type I-I & 88 & $9.70 \%$ \\
\hline Type II-II & 12 & $1.60 \%$ \\
\hline Type III-III & 2 & $2.40 \%$ \\
\hline Type IV-IV & 3 & $7.20 \%$ \\
\hline Puborectal muscle dominated FDD & 9 & $5.60 \%$ \\
\hline Type I-III & 7 & $1.60 \%$ \\
\hline Type II-IV & 2 & $8.10 \%$ \\
\hline Anal sphincter dominated FDD & 10 & $0.80 \%$ \\
\hline Type III-I & 1 & $7.30 \%$ \\
\hline
\end{tabular}

Strength of defecatory propulsive force strongly correlated with pressure increase at the level of the puborectal muscle

We observed that the strength of the defecatory propulsive force strongly correlated with the pressure increase at the level of the puborectal muscle $(\rho=0.794 ; p<0.001)$, as measured with the defecometry test. The correlation between the strength of the defecatory propulsive force and pressure increase at the level of the external anal sphincter was also significant, but weak $(\rho=0.488 ; p<0.001)$ (Figure 3).

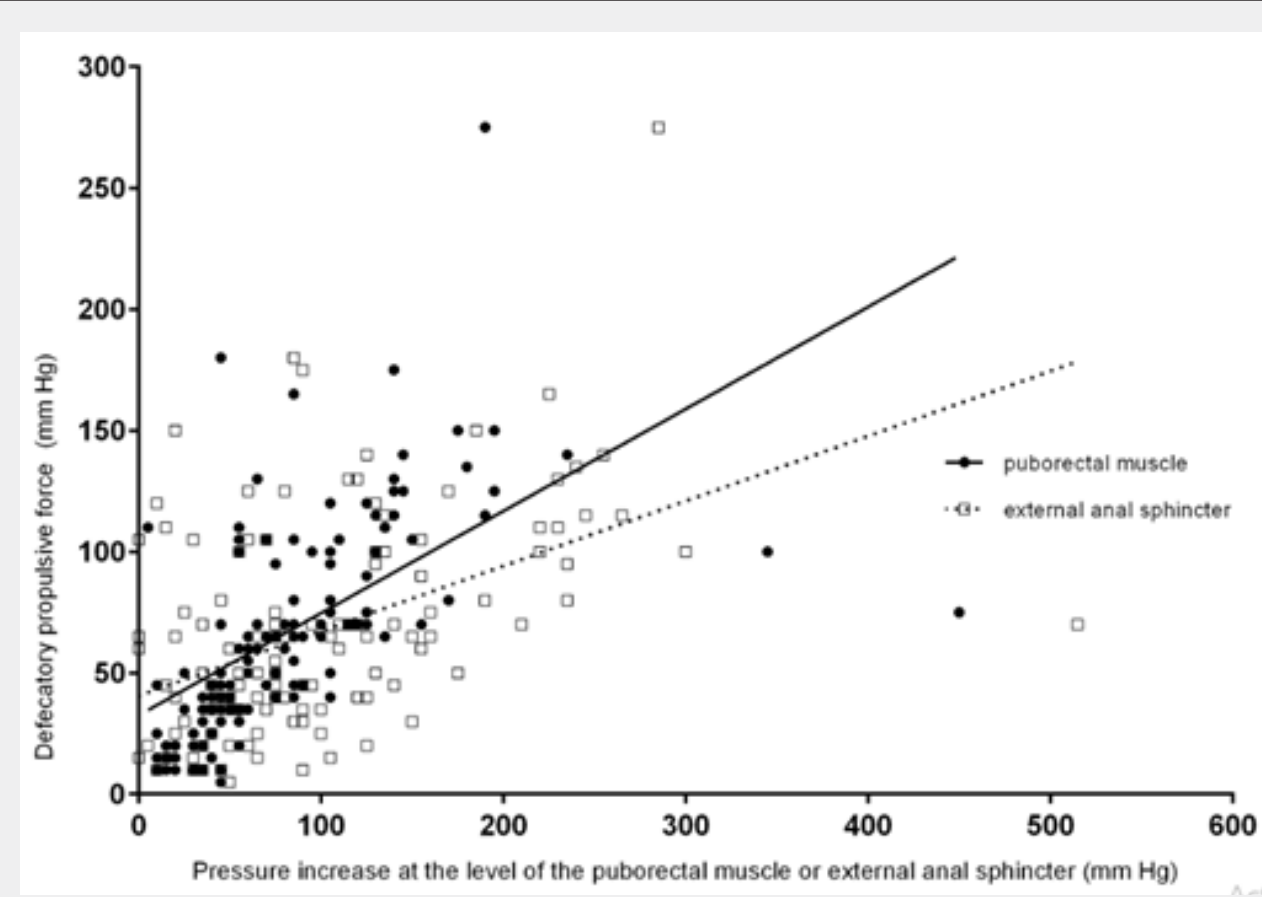

Figure 3: Correlation between the strength of the defecatory propulsive force and pressure increase at the level of the puborectal muscle and external anal sphincter. 
In addition, the defecatory propulsive force in patients who suffered from anal sphincter-dominated FDD was significantly weaker compared to patients suffering from congruent FDD ( $p$ $<0.001$ ) or puborectal muscle-dominated FDD ( $\mathrm{p}=0.008)$ (Table 2 ). The proportion of patients in the group of anal sphincterdominated FDD, who met the criteria for inadequate defecatory propulsion, was significantly higher than that of the group with congruent FDD $(p<0.001)$ and the group of puborectal muscledominated FDD $(\mathrm{p}=0.005)$. In the group of puborectal muscle dominated FDD, two out of nine patients met these criteria. These were the same two patients who were unable to evacuate the balloon during the defecometry test.

Table 2: Comparison between congruent, puborectal muscle-dominated, and anal sphincter-dominated functional defecation disorders.

\begin{tabular}{|c|c|c|c|c|c|c|c|c|c|}
\hline & \multicolumn{2}{|c|}{ (1) Congruent } & $\mathbf{p}$ & \multicolumn{2}{|c|}{$\begin{array}{l}\text { (2) Puborectal Mus- } \\
\text { cle-Dominated }\end{array}$} & $\mathbf{p}$ & \multicolumn{2}{|c|}{$\begin{array}{l}\text { (3) Anal Sphincter-Dom- } \\
\text { inated }\end{array}$} & $\mathbf{p}$ \\
\hline Frequency & \multicolumn{3}{|c|}{$\mathbf{n}$} & \multicolumn{3}{|c|}{$\mathbf{n}$} & \multicolumn{3}{|c|}{$\mathbf{n}$} \\
\hline Number of patients & \multicolumn{3}{|c|}{105} & \multicolumn{3}{|c|}{9} & \multicolumn{3}{|c|}{10} \\
\hline Demographics & n (\%) & $\operatorname{m}(\min -\max )$ & 1 vs. 2 & n (\%) & $\operatorname{m}(\min -\max )$ & 2 vs. 3 & n (\%) & $m(\min -\max )$ & 1 vs. 3 \\
\hline Number of females (\%) & \multicolumn{2}{|c|}{$84(80.0 \%)$} & 0.03 & \multicolumn{2}{|c|}{$4(44.4 \%)$} & NS & \multicolumn{2}{|r|}{$9(90.0 \%)$} & NS \\
\hline Age (years) & 105 & $57(18-81)$ & NS & 9 & $52(26-73)$ & NS & 10 & $62.5(27-76)$ & NS \\
\hline Anorectal manometry & n (\%) & m (min - max) & 1 vs. 2 & n (\%) & m (min - max $)$ & 2 vs. 3 & n (\%) & $\operatorname{m}(\min -\max )$ & 1 vs. 3 \\
\hline Basal pressure (mm Hg) & 105 & $50(10-115)$ & NS & 9 & $60(40-90)$ & NS & 10 & $42.5(20-60)$ & NS \\
\hline $\begin{array}{l}\text { Squeezing force (mm } \\
\mathrm{Hg})\end{array}$ & 104 & $160(40-465)$ & NS & 9 & $200(65-350)$ & NS & 10 & $127.5(50-245)$ & NS \\
\hline $\begin{array}{l}\text { Length sphincter com- } \\
\text { plex }(\mathrm{cm})\end{array}$ & 105 & $3.0(2.5-4.0)$ & 0.01 & 9 & $3.5(2.5-5.0)$ & NS & 10 & $3.0(2.5-4.0)$ & NS \\
\hline $\begin{array}{l}\text { Number of patients with } \\
\text { rectocele }(\%)\end{array}$ & \multicolumn{2}{|c|}{$93(88.6 \%)$} & NS & \multicolumn{2}{|c|}{$8(88.9 \%)$} & NS & \multicolumn{2}{|r|}{$9(90.0 \%)$} & NS \\
\hline Defecometry test & n (\%) & $\operatorname{m}(\min -\max )$ & 1 vs. 2 & n (\%) & $\operatorname{m}(\min -\max )$ & 2 vs. 3 & n (\%) & m (min - max $)$ & 1 vs. 3 \\
\hline $\begin{array}{l}\text { Patients capable of } \\
\text { expulsion (\%) }\end{array}$ & \multicolumn{2}{|c|}{$97(92.4 \%)$} & NS & \multicolumn{2}{|c|}{$7(77.8 \%)$} & NS & \multicolumn{2}{|r|}{$9(90.0 \%)$} & NS \\
\hline Expulsion volume (mL) & 97 & $50(50-150)$ & NS & 7 & $50(50-200)$ & NS & 9 & $50(50-100)$ & NS \\
\hline Expulsion time (sec) & 97 & $16(1.5-130)$ & NS & 7 & $21(8-51)$ & NS & 7 & $18(1-49)$ & NS \\
\hline $\begin{array}{l}\text { Defecatory propulsive } \\
\text { force }(\mathrm{mm} \mathrm{Hg})\end{array}$ & 105 & $65(5-275)$ & NS & 9 & $65(15-150)$ & 0.008 & 10 & $15(10-100)$ & $<0.001$ \\
\hline $\begin{array}{l}\text { Max. pressure rectum } \\
(\mathrm{mm} \mathrm{Hg})\end{array}$ & 105 & $95(25-315)$ & NS & 9 & $105(35-190)$ & NS & 10 & $55(40-125)$ & 0.001 \\
\hline $\begin{array}{c}\text { Inadequate propulsive } \\
\text { force }(\%)\end{array}$ & \multicolumn{2}{|c|}{$15(14.3 \%)$} & NS & \multicolumn{2}{|c|}{$2(22.2 \%)$} & 0.005 & \multicolumn{2}{|r|}{$9(90.0 \%)$} & $<0.001$ \\
\hline $\begin{array}{c}\text { Pressure increase } \\
\text { puborectal muscle (mm } \\
\mathrm{Hg})\end{array}$ & 105 & $75(5-450)$ & NS & 9 & $65(30-195)$ & $<0.001$ & 10 & $17.5(10-55)$ & $<0.001$ \\
\hline $\begin{array}{l}\text { Max. pressure puborec- } \\
\text { tal muscle (mm Hg) }\end{array}$ & 105 & $105(25-495)$ & NS & 9 & $120(45-240)$ & 0.002 & 10 & $45(30-75)$ & $<0.001$ \\
\hline $\begin{array}{l}\text { Pressure increases anal } \\
\text { sphincter }(\mathrm{mm} \mathrm{Hg})\end{array}$ & 105 & $90(10-515)$ & $<0.001$ & 9 & $5(0-75)$ & 0.007 & 10 & $50(20-220)$ & 0.05 \\
\hline $\begin{array}{l}\text { Max. pressure anal } \\
\text { sphincter (mm Hg) }\end{array}$ & 105 & $175(45-665)$ & $<0.001$ & 9 & $100(50-130)$ & NS & 10 & $105(65-325)$ & 0.01 \\
\hline
\end{tabular}

Male patients had a stronger defecatory propulsive force and built up more pressure at the level of the puborectal muscle

The defecometry test showed that in male patients who suffered from FDDs the defecatory propulsive force was significantly stronger than in female patients $(\mathrm{p}<0.001)$ (Table 3). Male patients also built up more pressure at the level of the puborectal muscle during defecation $(\mathrm{p}=0.003)$, whereas pressure increase at the level of the external anal sphincter was like that of female patients. In addition, the proportion of male patients in the group of puborectal muscle dominated FDD was significantly higher than the proportion of male patients in the congruent FDD group ( $p=0.03$ ) (Table 2). The difference in proportion of male patients between the group of puborectal muscle-dominated FDD and the group of anal sphincter-dominated FDD tended towards statistical significance $(\mathrm{p}=0.06)$. 
Table 3: Gender differences in functional defecation disorders.

\begin{tabular}{|c|c|c|c|}
\hline & Female Patients (min-max) & p & Male Patients (min-max) \\
\hline Defecatory propulsive force (mm Hg) & $50(5-275)$ & $<0.001$ & $100(35-180)$ \\
\hline Pressure increase puborectal muscle (mm Hg) & $60(5-450)$ & 0.003 & $105(25-195)$ \\
\hline Pressure increases external anal sphincter (mm Hg) & $75(0-515)$ & NS & $85(0-265)$ \\
\hline
\end{tabular}

\section{Discussion}

With this study we demonstrate that the puborectal muscle and external anal sphincter do not act as a single functional unit in patients suffering from FDDs. Our retrospective assessment of 124 patients with FDDs reveals that both muscles can, in fact, act independently of each other, be it functional or dysfunctional.

\section{Congruent FDD, puborectal muscle-dominated FDD, and anal sphincter-dominated FDD}

Current classifications of FDDs distinguish dyssynergic defecation and inadequate defecatory propulsion (Rome III classification) or FDD Types I, II, III, and IV (Rao's classification) $[9,10]$. Both classifications only consider pressure changes in the rectum and at the level of the external anal sphincter. They ignore pressure changes at the level of the puborectal muscle, on the assumption that these changes are like those of the external anal sphincter since the two muscles are thought to act as a single functional unit.

The above-mentioned classifications indeed allowed for the accurate classification of most of the patients studied (84.7\%). In these patients the puborectal muscle and external anal sphincter were equally dyssynergic: congruent FDD. A significant proportion of patients in our small cohort, however, suffered from puborectal muscle-dominated FDD (7.2\%) or anal sphincter-dominated FDD (8.1\%). In these patients either the puborectal muscle or the external anal sphincter was affected significantly more than the other. In fact, these results, which we obtained mainly with the defecometry test, disproved the assumption that the puborectal muscle and external anal sphincter act as a single functional unit. Therefore, to further improve the diagnostic power and treatment outcome of FDDs, we recommend adopting the new classification for FDDs as proposed by us in this study.

\section{Puborectal muscle dyssynergia obstructs defecation more than external anal sphincter dyssynergia}

With this study we also demonstrate that pressure increase at the level of the puborectal muscle correlates more strongly with the defecatory propulsive force than pressure increase at the level of the external anal sphincter. In other words, isolated high pressure at the level of the puborectal muscle requires a stronger defecatory propulsive force, i.e., impedes defecation more, than isolated external anal sphincter contraction. This observation agrees with differences in the adequacy of the defecatory propulsion force between patients suffering from the three main groups of FDDs we identified. In the groups of congruent FDD and puborectal muscledominated FDD, most patients, $85.7 \%$ and $77.8 \%$, respectively, generated an adequate defecatory propulsion force and, therefore, we classified them as Types I-I and I-III, respectively. In the group of anal sphincter-dominated FDD, however, virtually all patients, $90.0 \%$, met the criteria for inadequate defecatory propulsion and, therefore, we classified them as Type IV-II.

Thus, isolated dyssynergia at the level of the puborectal muscle obstructed defecation more than isolated external anal sphincter dyssynergia. The question arose whether this was also reflected in the symptoms experienced by the patients in the different groups. It could be hypothesized that patients suffering from congruent FDD or puborectal muscle-dominated FDD had a lower stool frequency, had to strain harder and/or longer, or experience a feeling of incomplete evacuation more often than patients suffering from anal sphincter-dominated FDD. Further research is necessary to determine whether this is the case.

\section{Male patients are more likely to suffer from puborectal muscle-dominated FDD}

Male subjects are known to have a significantly longer anal sphincter and to generate significantly higher maximum squeeze pressures than female subjects [16-18]. Studies on possible gender differences in defecatory propulsion force reported conflicting results $[16,18]$. Our study demonstrates that male patients suffering from FDD not only generate a significantly stronger defecatory propulsion force than female patients, but they also build up significantly more pressure at the level of the puborectal muscle during defecation. The latter is reflected by the proportion of male patients in the group of puborectal muscle dominated FDD. It is significantly higher than the proportion of male patients in the group of congruent FDD. The difference in proportions of male patients between the group of puborectal muscle-dominated FDD and the group of anal sphincter-dominated FDD tends towards statistical significance.

\section{Clinical Implications}

Our main finding is the fact that the puborectal muscle and external anal sphincter can act independently of one another, be it functionally or dysfunctional. This finding is supported by recent report of Fernández-Fraga et al, who observed that the strength of the voluntary contractions can have a different pattern [19]. In our opinion, this finding necessitates modification of the current classification and replacing it with a new classification system for FDD that would improve the diagnostics and treatment outcome of FDD patients. The classification for FDDs we propose in this study and which distinguishes between congruent FDD, puborectal muscle-dominated FDD, and anal sphincter- 
dominated FDD, is preferable to the classifications currently in use. To prevent patients with puborectal muscle-dominated FDD or anal sphincter-dominated FDD from being assessed incorrectly, it is imperative to always perform anorectal manometry which measures pressure changes in the rectum, pressure changes at the level of the puborectal muscle and pressure changes at the level of the external anal sphincter.

The defecometry test, which combines anorectal manometry with the balloon expulsion test, seems best suited for accurate diagnosis and classification into these new FDD groups. Importantly, current biofeedback therapy often relies on the use of single probe electromyographic devices $[20,21,23]$. The anal probe of these devices is so long that the electromyographic activity of the puborectal muscle and external anal sphincter is recorded together and, since it is a single probe system, is added up. This makes such equipment theoretically unsuitable for the treatment of patients suffering from puborectal muscle-dominated FDD or anal sphincter-dominated FDD. It might, in fact, explain why 20 to $30 \%$ of patients with FDDs have little or no benefit from biofeedback therapy [20-23]. To reduce this percentage of nonresponders, new equipment should be developed which would enable rapid and accurate recording of the activity of the rectum, the puborectal muscle, and the external anal sphincter separately.

\section{Conclusion}

In conclusion, we demonstrate that the puborectal muscle and external anal sphincter can function independently of one another and can contribute to FDDs separately. Based on this finding we propose a new FDD classification, designed with a view to improve diagnosis and treatment outcome.

\section{Acknowledgement}

The authors thank Mrs. O.J. Pras for her substantial assistance in the manometry laboratory and T. van Wulfften Palthe, PhD, for correcting the English manuscript.

\section{Compliance with Ethical Standards}

All procedures performed in studies involving human participants were in accordance with the ethical standards of the institutional and/or national research committee and with the 1964 Helsinki declaration and its later amendments or comparable ethical standards. For this type of study, formal consent is not required.

\section{References}

1. Surrenti E, Rath DM, Pemberton JH, M Camilleri (1995) Audit of constipation in a tertiary referral gastroenterology practice. Am J Gastroenterol 90: 1471-1475.

2. Kuijpers HC (1990) Application of the colorectal laboratory in diagnosis and treatment of functional constipation. Dis Colon Rectum 33: 35-39.

3. Koch A, Voderholzer WA, Klauser AG, S Müller Lissner (1997) Symptoms in chronic constipation. Dis Colon Rectum 40: 902-906.

4. Nyam DC, Pemberton, JH, Ilstrup DM, D M Rath (1997) Long-term results of surgery for chronic constipation. Dis Colon Rectum 40: 273279 .
5. Rao SS, Tuteja AK, Vellema T, Joan Kempf, Mary Stessman (2004) Dyssynergic defecation: demographics, symptoms, stool patterns and quality of life. J Clin Gastroenterol 38: 680-685.

6. Rao SS, Welcher K, Leistikow J (1998) Obstructive defecation: a failure of rectoanal coordination. Am J Gastroenterol 93: 1042-1050.

7. Read NW, Celik AF, Katsinelos P (1995) Constipation and incontinence in the elderly. J Clin Gastroenterol 20: 61-70.

8. Yu SW, Rao SS (2014) Anorectal physiology and pathophysiology in the elderly. Clin Geriatr Med 30: 95-106.

9. Rao SS, Bharucha AE, Chiarioni G, Richelle Felt Bersma Charles Knowles, et al. (2016) Anorectal disorders. Gastroenterology 150: 1430-1442.

10. Rao SS (2008) Dyssynergic defecation and biofeedback therapy. Gastroenterol Clin North Am 37: 569-586.

11. Penninckx FM, Lestar B, Kerremans RP (1989) A new balloon-retaining test for evaluation of anorectal function in incontinent patients. Dis Colon Rectum 32: 202-205.

12. Broens PM, Penninckx FM, Lestar B, R P Kerremans (1994) The trigger for rectal filling sensation. Int J Colorectal Dis 9: 1-4.

13. Broens P, Vanbeckevoort D, Bellon E, Freddy Penninckx (2002) Combined radiologic and manometric study of rectal filling sensation. Dis Colon Rectum 45: 1016-1022.

14. Rao SS, Ozturk R, Laine L (2005) Clinical utility of diagnostic tests for constipation in adults: a systematic review. Am J Gastroenterol 100: $1605-1615$

15. Rao SS, Mudipalli RS, Stessman M, B Zimmerman (2004) Investigation of the utility of colorectal function tests and Rome II criteria in dyssynergic defecation (Anismus). Neurogastroenterol Motil 16: 589596.

16. Rao SS, Hatfield R, Soffer E, S Rao, J Beaty, et al. (1999) Manometric tests of anorectal function in healthy adults. Am J Gastroenterol 94: 773-783.

17. Gundling F, Seidl H, Scalercio N, T Schmidt, W Schepp, et al. (2010) Influence of gender and age on anorectal function: normal values from anorectal manometry in a large Caucasian population. Digestion 81: 207-213.

18. Li Y, Yang X, Xu C, Yi Zhang, Xipeng Zhang (2013) Normal values and pressure morphology for three-dimensional high-resolution anorectal manometry of asymptomatic adults: a study in 110 subjects. Int J Colorectal Dis 28: 1161-1168.

19. Fernández Fraga X, Azpiroz F, Malagelada JR (2002) Significance of pelvic floor muscles in anal incontinence. Gastroenterology 123: 14411450.

20. Heymen S, Scarlett Y, Jones K, Yehuda Ringel, Douglas Drossman, et al. (2007) Randomized, controlled trial shows biofeedback to be superior to alternative treatments for patients with pelvic floor dyssynergiatype constipation. Dis Colon Rectum 50:428-441.

21. Chiarioni G, Salandini L, Whitehead WE (2005) Biofeedback benefits only patients with outlet dysfunction, not patients with isolated slow transit constipation. Gastroenterology 129: 86-97.

22. Rao SS, Seaton K, Miller M, Kice Brown, Ingrid Nygaard, et al. (2007) Randomized controlled trial of biofeedback, sham feedback, and standard therapy for dyssynergic defecation. Clin Gastroenterol Hepatol 5: 331-338.

23. Chiarioni G, Whitehead WE, Pezza V, Antonio Morelli, Gabrio Bassotti, et al. (2006) Biofeedback is superior to laxatives for normal transit constipation due to pelvic floor dyssynergia. Gastroenterology 130: 657-664. 
This work is licensed under Creative Commons Attribution 4.0 License DOI:10.19080/ARGH.2021.16.555945
Your next submission with JuniperPublishers will reach you the below assets

- Quality Editorial service

- Swift Peer Review

- Reprints availability

- E-prints Service

- Manuscript Podcast for convenient understanding

- Global attainment for your research

- Manuscript accessibility in different formats ( Pdf, E-pub, Full Text, audio)

- Unceasing customer service

Track the below URL for one-step submission https://juniperpublishers.com/online-submission.php 